Ángel Verdasco

Ángel Verdasco es doctor arquitecto por la ETSAM y profesor de Proyectos Arquitectónicos en las Escuelas de Alcalá y Europea de Madrid.

\title{
A la búsqueda de un método Dialéctica entre composición, materia y construcción en Curro Inza
}

Palabras clave: Inza, composición, materia, construcción, forma, Brutalismo, economía de medios, Café Gijón, Galería de Arte Sacro.

Este artículo se suma a la relectura que se está llevando a cabo en tiempos recientes sobre lo que se denominó organicismo madrileño y Escuela de Madrid de los años 60 y 70 del s.XX. El trabajo se centra en uno de los personajes más significativos: el arquitecto Curro Inza. Se analiza en dos de sus obras de juventud la relación que establece entre composición, materia y construcción, en un intento de aproximarnos con mayor acierto a su enigmática arquitectura orgánica y explicar las razones proyectuales que en ella subyacen. Todo ello, junto con el reconocimiento de una toma de postura matérica cercana al brutalismo, permite desmontar algunas percepciones actuales sobre su trabajo, a la vez que posibilita reconocer estrategias arquitectónicas de candente actualidad.

\section{Introducción}

a manera de afrontar el proyecto (un -método si existiese) y la postura del arquitecto sobre la materialidad establecen una serie de relaciones de orden constructivo y formal que en ocasiones se convierten en el motivo central desde el que entender los proyectos de arquitectura de un autor.

Arquitectos de muy diversa indole (lo cual confirma el calado del debate) han centrado su atención en establecer una dialéctica entre materia, forma y construcción que, si dejásemos de atender, convertiría sus arquitecturas en ininteligibles. $\mathrm{O}$ dicho de otro modo: es desde esa dialéctica desde donde mejor se pueden explicar sus arquitecturas.

Este artículo se pregunta, y analiza, la relación entre forma y construcción en la obra del arquitecto Curro Inza. Un arquitecto por explicar y sobre el que ahora se están releyendo y estudiando sus obras (Autor, 2013). Creemos que el debate interno que se establece entre forma $\mathrm{y}$ construcción es determinante para entender todo el discurso que sujeta su trabajo.

Dada la precocidad de estos intereses desde los primeros trabajos del autor, se plantea aquí un estudio crítico y minucioso de dos de sus primeras obras construidas. A través de ellas se pretende entender y explicar algunas decisiones proyectuales y su postura critica como arquitecto. Por ello si bien este escrito trata de un caso bien concreto, Inza no deja de ser un ejemplo y una excusa, pues de este estudio se desprende una manera de hacer arquitec- tura que bien podríamos encontrar en otros autores bien dispares.

La primera hipótesis de este texto es que Inza buscará desde el principio un método para acometer sus proyectos. Un método que parte siempre de premisas constructivas y que se establece como ley a lo largo del proyecto. La consecuencia directa es que se acomete el encargo sin forma previa, siendo ésta el resultado de las premisas dictadas por el método intelectual y constructivo.

La segunda hipótesis apunta a la clara mirada brutalista del autor sobre la materia y cómo esta se maneja como herramienta arquitectónica.

Es interesante destacar esta cualidad en su obra y este determinismo dónde lo formal no interesa en si mismo y únicamente interesa como resultado. De este modo la forma como discusión estética queda fuera de la discusión arquitectónica y sólo tiene interés como resultado de una interrelación establecida con la construcción.

Estas pautas juveniles (búsqueda de un método y posicionamiento matérico) se convertirán en dos de las características principales para entender todo su trabajo.

Parece pertinente una explicación sobre su mirada rigurosa en la relación forma-construcción pues Inza perteneció al organicismo madrileño (Fullaondo, 1968) y en ocasiones, como veremos a continuación, a estos arquitectos se les han supuesto unas arquitecturas más laxas y proclives a la forma por la forma: "En obras como el Café Gijón en Madrid en 1962, o el Hotel Alfaro 
Figura 1.Galería de Arte Sacro. Archivo Inza. Biblioteca ETSAM. en Logroño, de 1968, demostró Inza que su aproximación a lo orgánico provenía más de su exuberante humanidad que de una decisión de coyuntura cultural" (Ruíz Cabrero 2001).

Las primeras visiones, superficiales, de la obra de Inza, inducen a entender su trabajo como algo arbitrario donde la toma de decisiones es circunstancial y caprichosa. Hasta ahora algunos autores (Bohigas, 1996; Ruiz Cabrero, 2001), sin posibilidad quizás de indagar demasiado en los orígenes, han presentado el trabajo de Inza como una consecuencia de su acusada personalidad y como una opción aleatoria elegida azarosamente. Todo ello ha extendido sobre su trabajo un estigma de formalista provocando rechazo e impidiendo descubrir su metodología proyectual.

El estudio del archivo personal del arquitecto y de sus textos, facilitan por vez primera preguntarse qué criterio sigue el autor a la hora de proyectar. Dos modestos ejemplos construidos de su obra temprana, como la galería de Arte Sacro y la reforma del Café Gijón, permiten indagar en esa aproximación al proyecto y en la idea de que Inza buscará en todos sus encargos un método material y proyectual, que le permita encarar el proyecto de manera rigurosa y a la vez flexible.

Desmontando esa primera percepción citada, veremos que la búsqueda de un método que liga construcción, materia y forma, se convertirá en una de las características principales de sus obras.

\section{Primera aproximación: La galería de Arte Sacro}

En 1961-62 realiza Inza la reforma de un local comercial en Madrid que a la postre será el inicio de una serie de tiendas que construirá a lo largo de la geografia española para Tapicerías Gancedo.

El local, a pie de calle, estaba dedicado a la venta de telas. Bajo él se pretendía construir un sótano donde ubicar una galería de Arte Sacro llamada "Templo y Altar". ${ }^{1}$ Este encargo procedía, como casi todos los de su carrera, de una relación personal, en este caso de su relación con el franciscano José Manuel de Aguilar, O.P.

A mediados de 1959 Aguilar pidió consejo a su amigo Carlos de Miguel para fundar la revista ARA, dedicada al Arte Religioso que pretendía desde un planteamiento actual abordar los problemas del momento, y necesitaba contacto con arquitectos jóve-

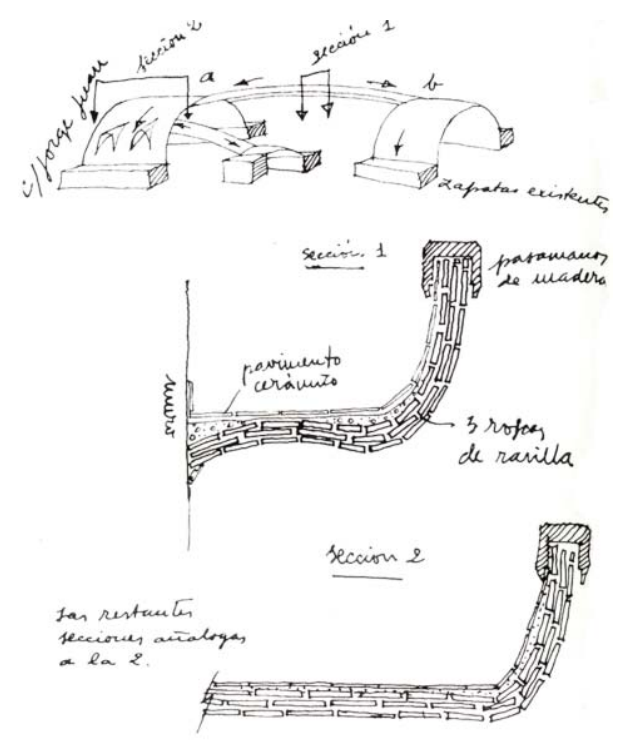

nes cuyas obras mereciesen darse a conocer y cuyos puntos de vista pudiesen comentarse y discutirse. En la primera contestación de Miguel le dijo: "pues precisamente tengo ahora mismo conmigo en la revista (Arquitectura) un muchacho de inquietudes religiosa y estéticas, de cualidades muy apropiadas para lo que me pides" (Aguilar 1978). A partir de ahí establecieron amistad y poco tiempo después entraron en un equipo de colaboración promovido por Pepe Gancedo y Fernando Álvarez Alba, para el desarrollo de una instalación comercial con amplio desarrollo espacial, y en el cuál se les daba la oportunidad de promover la mencionada galería de arte religioso como lugar para el diálogo, los debates y las exposiciones de jóvenes artistas.

Colaboraron estrechamente durante los siguientes meses, cimentando una amistad y afinidad en criterios, según Aguilar enfocados "para la tarea de renovación en la estética religiosa en España" y donde Inza terminará haciendo una "excelente obra preconciliar, inspirada en un nuevo sentido y que vendría a resultar muy conforme con la ya próxima orientación del Concilio Vaticano II" (Aguilar 1978).

El proyecto de la galería de Arte Sacro consistía en crear un sótano y la escalera que lo enlazase con la planta superior de ventas de telas. Inza plantea dos decisiones determinantes en el comienzo del proyecto: la elección de un tipo estructural y la elección del material. El autor explica (figuras 1 y 2):

"Aprovechando unos sótanos se trataba de organizar una disposición de locales de objetos de arte sacro. Las poderosas zapatas del edificio dieron pie para emplear un sistema de bóvedas tabicadas, siste- 
Figura 2. Galeria de Arte Sacro. Archivo Inza. Biblioteca ETSAM

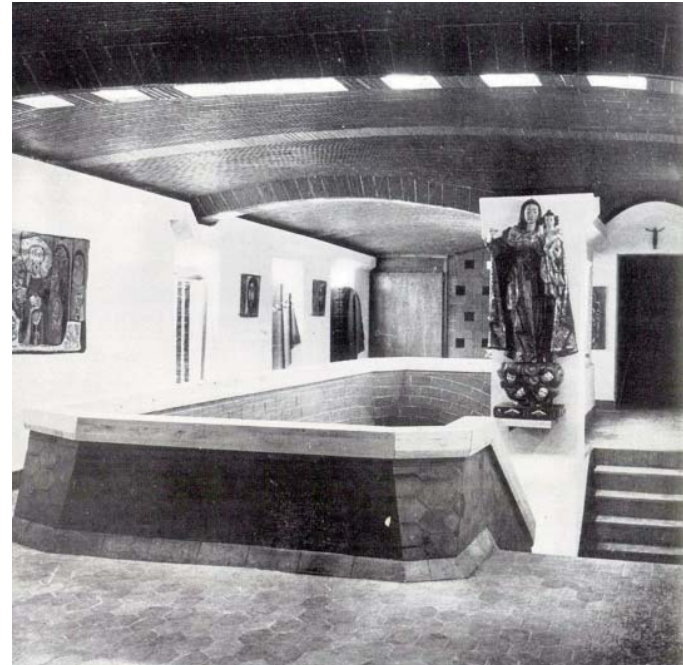

ma de otra parte muy conforme a mi juicio con el destino del local. Partiendo de las dos zapatas de muros de carga perpendiculares a la calle de Jorge Juan, se tendieron dos bóvedas tabicadas: la primera de cañón, con lunetos, y la segunda rebajada en escarzano. Ambas de tres roscas de rasilla.

Era necesario enlazar ambas con un pasillo que permitiera la circulación completa por la sala. Y a la vez el aprovechamiento para exposición del muro. Dicho pasillo es una bóveda que se apoya en las dos anteriores, y salva una luz de ocho metros de flecha. Su sección transversal es muy semejante a la sección 1 del croquis.

Esta bóveda, como las demás, se tendió a sentimiento y con una cimbrilla de listón. Propiamente tal vez no deba llamarse bóveda. Es más bien una pieza de sección como de media U trabajando en arco, así que su resistencia es muy grande.

Gracias a la forma de sus secciones transversales, ha sido posible rebajar la relación luz flecha casi en la razón veinticinco a uno. Esto no ha sido por hacer un alarde, sino porque era fundamental el reducir la flecha para que pudiera funcionar como pasillo". (Inza 1962)

Plantas Galeria Arte Sacro
A pesar de las exageradas formas resultantes cabe señalar como una característi- ca de los trabajos de Inza el hecho de apoyarse siempre en un antecedente. En este caso, unos pilares que determinan el sistema estructural.

La solución estructural es clara y rotunda y la forma resultante es consecuencia de dicha estrategia. El uso de las bóvedas puede proceder de su proyecto del Comedor de la Mesquida (1958), 2 y de lo vernáculo catalán, aunque también podría pesar, como se ha señalado (Tena 1999), la posible influencia de Luis Moya al que Inza frecuentó en la redacción de la revista Arquitectura.

La segunda decisión del proyecto que alude al planteamiento material de la galería de Arte Sacro está inevitablemente ligado al debate paralelo que se dio en esos años sobre si los materiales a utilizar en la arquitectura religiosa debian ser ricos o pobres. La idea predominante era que debían ser pobres y austeros y se basaba en el razonamiento de que Jesús, Hijo de Dios, había nacido, vivido y muerto en la absoluta pobreza y por tanto la iglesia que era la Casa de Dios debería ser igual de pobre.

"La pobreza, como condición necesaria de una iglesia es cosa de hoy. La tradición quería las iglesias tan ricas como fuera posible, y esto desde las catacumbas. Se hizo siempre lo más y lo mejor dentro de las condiciones del lugar y del tiempo. Pero además se quería la sinceridad, y esto hacía más difícil el problema, pues obligaba a que la estructura fuera bella y rica en sí ya que no se podía revestir, como ahora se hace. Si la cubierta era una armadura de madera, ésta quedaba a la vista con toda su complicación, y también con toda su verdad (...) Ahora se busca una falsa sencillez revistiendo armaduras metálicas con cielos rasos, tanto en iglesias como en cines. Los antiguos no tenían miedo a la complicación cuando ésta era necesaria. De este modo sus estructuras eran expresivas de por sí, aún antes de añadir figuras y símbolos". (Moya 1963)

Esto también incumbia a los motivos ornamentales:

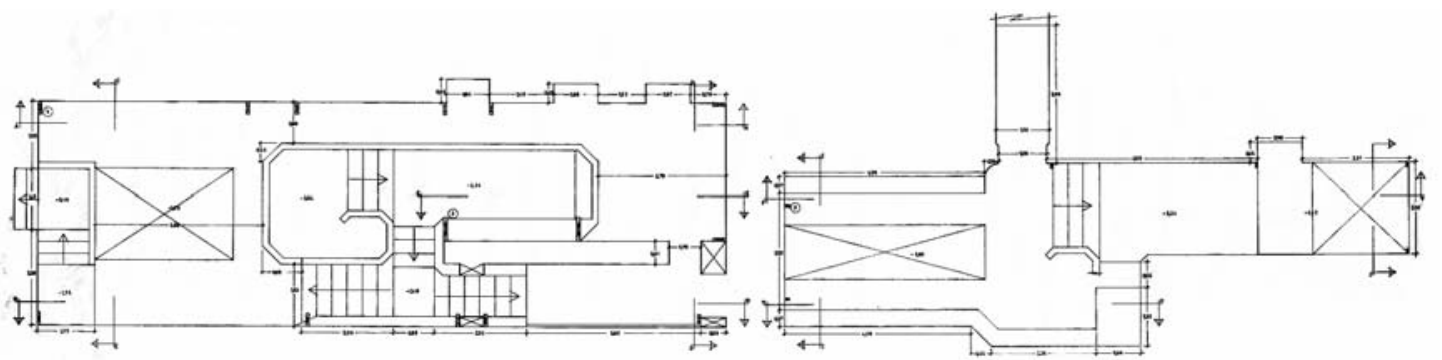


Figura 3. Galería de Arte Sacro. Archivo Inza. Biblioteca ETSAM

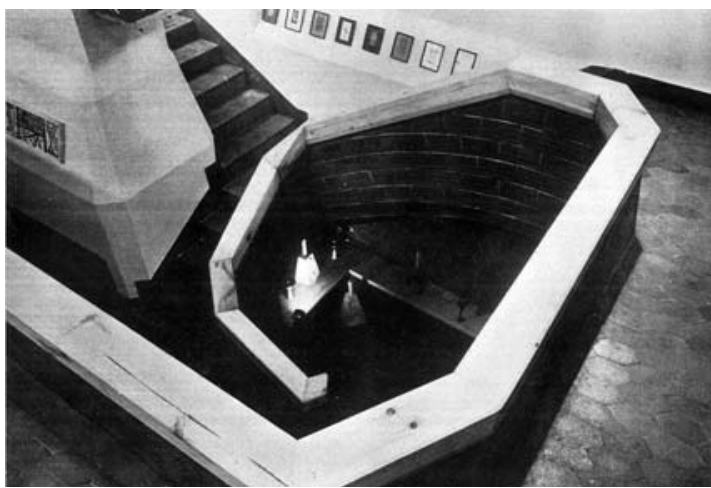

"La austeridad que hoy se propugna no debe tener por fin dejar las iglesias en un desangelado desmantelamiento, sino hacer posible y fomentar la experiencia profundamente humana del encuentro con Dios y con los demás hombres, a través de las diferentes formas de piedad, la liturgia y la popular. No debe confundirse la pureza con la elementalidad y la sobriedad con el desamparo. El exceso de motivos ornamentales ahoga el sentido del misterio, y la falta de todo apoyo sensible deja al hombre con frecuencia en una soledad vacía. Lo que procede es buscar un término medio". (López Quintans 1963)

Sobre los asuntos ornamentales se debe destacar un asunto conocido por Inza como era el ingente esfuerzo de Fernández del Amo invitando a participar a artistas modernos en las modestas iglesias de colonización (Centellas 2010). Y sobre los materiales adecuados a utilizar Inza apunta:

"Pobreza es la escasez o carencia de medios materiales.

Riqueza es la abundancia de bienes

Ostentación es la acción de hacer gala de grandeza y boato". (Inza 1963 a)

Para él, esta última no debería incluirse en la construcción de una iglesia, pero las otras dos no están separadas por una línea y admiten una escala de valores. El argumento predominante no le parece suficien-

Arte Sacro. Archivo

Inza. Biblioteca ETSAM

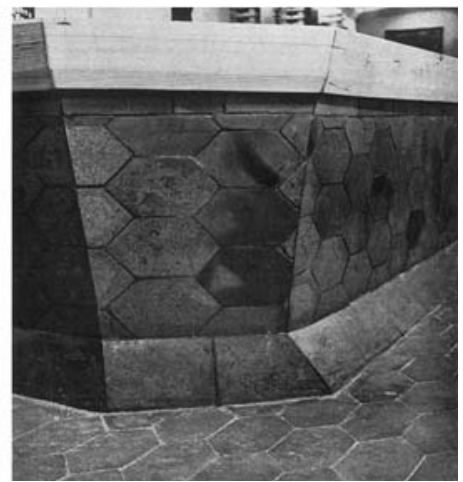

te para que se decida que las iglesias deban ser pobres. De hecho cree que las iglesias siempre habian tenido como finalidad dar gloria a Dios y nunca daban sensación de pobreza sino que nos sobrecogían con su magnificencia:

"Más bien los que clamamos por la pobreza de la iglesias somos los que pensamos que pueden resolverse a costa de estas otros problemas sociales de mayor urgencia. Eso sí, con nuestras espaldas bien cubiertas y acogiéndonos al argumento del santo portal de Belén.

Al tratar, pues, de los materiales para un edificio-iglesia, es a mi juicio totalmente necesario y justo que éstos sean dignos, y si además son ricos, mejor. Siempre y cuando no se supedite la magnificencia de la iglesia a la riqueza de los materiales que la constituyen, sino, por el contrario, que dicha magnificencia y hermosura tenga su apoyatura fundamental en la perfecta solución arquitectónica". (Inza 1963 a)

Para Inza el debate del material reproducía lo ocurrido en el s.XII entre dos monjes benedictinos: San Bernardo, por parte del Cister y el Abad Suger por parte de Cluny (Inza 1966). El primero optó por eliminar cualquier ornamentación del templo mientras el segundo emprendió un nuevo camino de búsqueda de la belleza. Para Inza, "la belleza también puede encontrarse en las complicadas, inverosímiles, dificilísimas formas de la orquídea. Extrañamente funcionales, asombrosamente hermosas. (..) Es por tanto a mi juicio, desde un punto de vista estético, mucho más interesante la segunda figura, aunque sus concepciones artísticas no sean del gusto de hoy" (Inza 1966).

Extrapolando los asuntos religiosos a otros tipos de espacios, cabria decir que el debate sobre la condición material de la arquitectura será un tema recurrente en la obra de Inza, siendo la galería de Arte Sacro su primer ejemplo (figuras 3 y 4).

La decisión sobre el material será la búsqueda de una economía de medios para realizar su arquitectura. Trabajará con pocos materiales exprimiendo su condición. En el sótano y la escalera de la galería utiliza solo rasillas que adquieren una condición estructural (la condición casi monomatérica ya estaba intuida en su Proyecto Fin de Carrera). ${ }^{3}$ En la memoria de la tienda de la planta superior dice: "Los materiales empleados fueron: granito en fachada -porque no queríamos emplear más que un solo material y existía ya un 


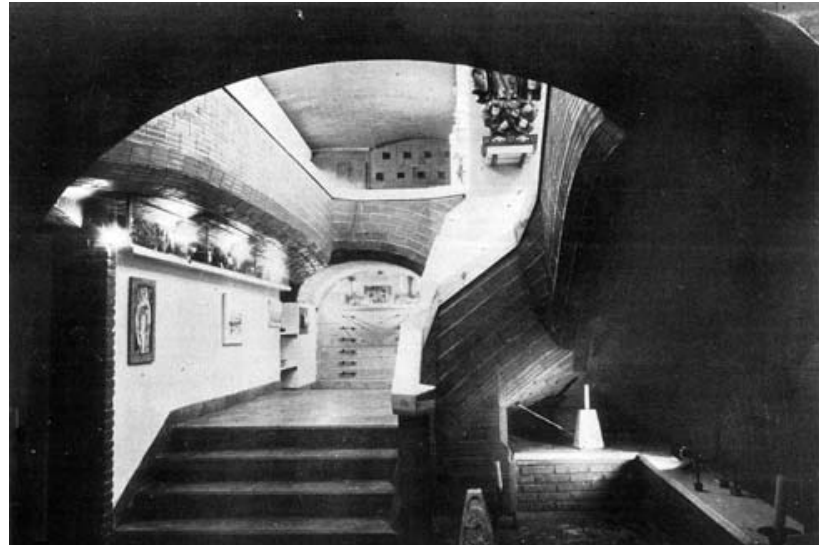

Figura 5. Galeria de Arte Sacro. Archivo Inza. Biblioteca ETSAM

Figura 6. Galería de Arte Sacro. Archivo Inza. Biblioteca ETSAM formidable zócalo de sillería- barro y pita en los pavimentos, yeso en las paredes y hierro en la carpintería" (Inza 1961). Como ocurría con las zapatas del sótano el autor parte de una preexistencia, en este caso el granito que ya existia. Inza parece interesado en no inventar situaciones sino en explotar las posibilidades de cada situación. Un detalle importante para entender su carrera.

La segunda decisión sobre el material parece ser la búsqueda de la sinceridad constructiva. Viendo los bocetos de los pasamanos y las barandillas se entiende su precoz interés por la posibilidad de resolver el problema con pocos sistemas constructivos: "La ejecución material de las bóvedas es verdaderamente estupenda. Así que van vistas y enceradas. El pavimento es cerámico, también encerado y con muros pintados de blanco" (Inza 1962). "Son bóvedas de doble curvatura, apoyadas una contra otra, y se dejaron vistas a causa de la fenomenal ejecución de las mismas. Las hizo un oficial de Badajoz" (Inza 1961).

Detrás de esa cuidada ejecución existe un planteamiento que deja vistos los procesos constructivos y los materiales, donde la verdad constructiva se muestra sin tapujos.

Y la tercera decisión sobre el material será la idea de "continuidad material". El propio Inza señala en la memoria del proyecto: "se pretendió también una unidad no solamente de materiales, sino de enlaces de unos con otros. Así por ejemplo los pavimentos, constituidos por piezas de barro cocido "suben" a su vez por los pasamanos de las escaleras". Andrés Perea, excolaborador de Inza, recordaba sus palabras: "Inza nos decia: fijaros en cómo se unen la uña y el dedo. Existe siempre una transición, como debería ocurrir en la arquitectura". ${ }^{4} \mathrm{El}$ autor lo confirma: "Se procuró a lo largo de toda la obra, un especial cuidado en resolver con mucho cariño los enlaces y la continuidad de materiales, para lo cual no fue posible en general, valerse de planos, sino más bien de pasar gran parte de la jornada con los operarios y dibujando muchas veces cada rasilla y cada baldosa cerámica" (Inza 1963 b).

Efectivamente esta aproximación al material tendrá como consecuencia que su arquitectura se haga prácticamente en obra y adquiera esa condición artesana. Esta forma de trabajar explica que la mayoria de sus proyectos existan sucesivas versiones y que no en todos ellos coincida el dibujo y lo construido. (El detalle de dar las gracias a las cuadrillas y los artesanos, y reflejarlo en las memorias publicadas será a partir de ahora habitual) (figuras 5 y 6).

La galería tuvo gran éxito y resonancia internacional, como por ejemplo en la revista belga Art d'Eglise donde se destaca su condición material:

"Un local muy acertadamente ambientado por Inza. Ambiente de especial intimidad y recogimiento, momentáneamente de respetuosidad casi sacra y otras de jovial discusión y amistosa consulta. Algo nuevo y dificil plenamente conseguido. Austeridad y sencillez en toda su arquitectura que, con materiales primarios, bóvedas de rasilla vistas, paredes encaladas, solados cerámicos y madera de pino consiguen alcanzar un clima de religiosidad y paz sumamente propicio para la presentación de las obras de arte religioso y objetos litúrgicos. Se suceden las exposiciones, los coloquios, la renovación de obras y ensayos de producción que hacen de Templo y Altar una institución viva y prometedora". (1963)
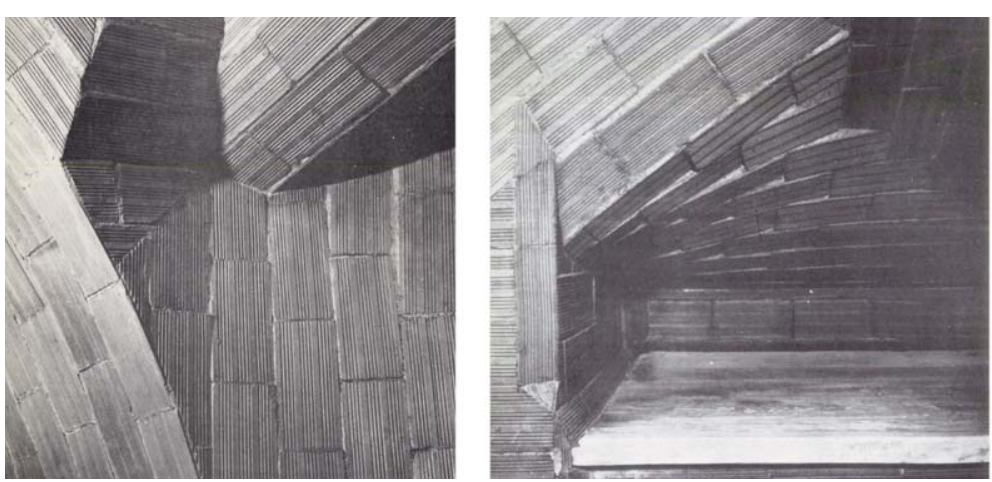


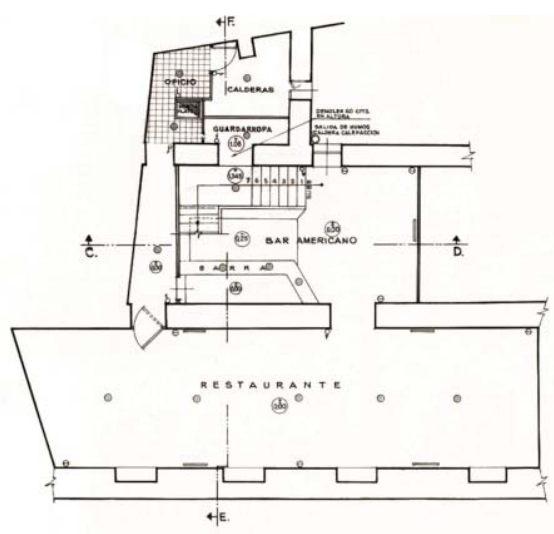

PROYECTO DE REFORMA DEL CAFE
GROY-AVENDA CALYO SOTELO PLANTA DE SOTANO

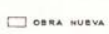

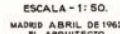

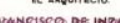

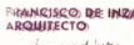
havaurlition

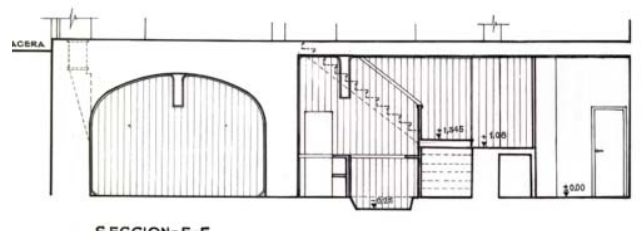

SECCION-E-F.

Figura XX. Café Gijón. Arriba. Planta estado reformado. Abajo. Sección

Figura 7. Café Gijón. Archivo Inza. Biblioteca ETSAM

\section{Depurando un discurso entre método, materia, forma y construcción}

La segunda obra que ayudará a explicar la búsqueda de un método es la reforma del Café Gijón en Madrid construido en 1962.5 Un café proyectado años antes por Carlos Arniches que era, y ha sido durante largo tiempo, un lugar frecuentado por artistas, literatos, politicos y gente del mundo de la cultura. De nuevo se le encarga a Inza que mantenga ese Café a nivel de calle e intervenga en el sótano, que en este caso ya existía, para acondicionar un restaurante:

"Arniches lo hizo muy bien...tenía la suficiente libertad de mano y de pensamiento como para pasar suavemente por encima de muchas recetas y modismos para situarse -con un fenomenal sentido común- en una posición sencilla y duradera. Arniches era inteligente. Arniches era un estupendo arquitecto. Así que cuando me encargaron el año pasado una reforma, decidieron no tocar apenas su obra; únicamente "lavarle la cara" al salón. Les pusimos un solado nuevo- del mismo color que el viejo-, tapizamos los divanes y las sillas de terciopelo colorado, pusimos unos globos blancos, como han tenido siempre los

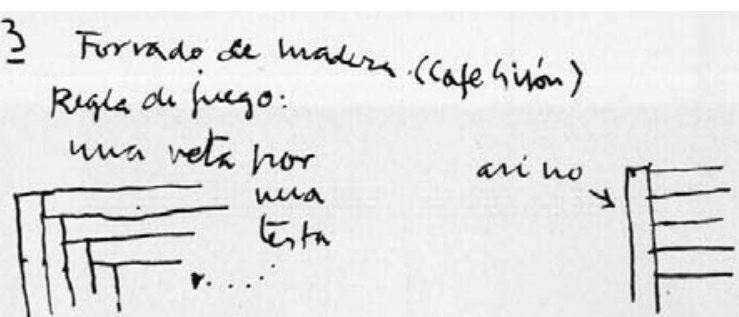

(tambien hay anomalias). buenos cafés europeos, quitamos unas "venecianas" y colocamos también cortinas de terciopelo en las ventanas". (Inza 1963 c)

De modo que en el salón hizo una mínima labor de conservación, acondicionó la cocina, los aseos y puso aire acondicionado. Abrió una escalera bastante amplia que comunicaba le salón y el restaurante que se ubicaría en el sótano. El sótano que habia servido hasta el momento para almacenar las sillas de la terraza, es donde realmente se acometa el proyecto. Era un espacio con bóveda de cañón, construida con tizones de ladrillo, que recorría toda la fachada con una longitud casi igual que la del salón, y otras dos habitaciones anexas. Comienza el proyecto diciendo que "si algún interés puede tener la obra nueva realizada es algo tan desprestigiado entre los periodistas como el 'revestimiento'. Me propuse utilizar un solo material en toda la obra externa. La elección del material me la proporcionó la obra antigua, así que decidí el mismo material que Arniches: el roble en tarima. Así 'forramos' todo el local de tarima de roble de $8 \mathrm{~cm}$ de tabla y 18 y 26 milimetros de canto" (Inza 1963 c).

De nuevo no muestra ningún reparo, todo lo contrario, en partir de lo preexistente para arrancar su proyecto. Y una vez asumido el carácter epitelial del mismo, fija un método de actuación a través de una regla (figura 7):

"Me pareció desde el principio que la luz de colocación y la luz de ejecución material eran las bases fundamentales de la obra (Proyecto, prácticamente, no existe). Así que con el objeto no solo de conseguir, sino continuidad absoluta del mismo, le colocamos según una regla que se cumple siempre, excepto en tres o cuatro puntos en los que se produce alguna anomalía. La regla es más o menos esta: una testa con una testa o una veta con una testa. Nunca más de una”. (Inza 1963 c)

Esta regla curiosamente no está especificada en la memoria del proyecto, pero si es la idea que aparece desde el primer boceto y sobrevuela todo este trabajo. Años después explicando su método dirá:

"Lo que hice fue plantearme unas reglas de juego: hacer ese sótano de una manera. Entonces yo estaba muy interesado por los problemas que presenta la continuidad de materiales. Y decidí hacer ese sótano de madera. Yo podía haber encargado que el recinto se forrase de determinada madera. Pero creí que debía dar más "datos" al carpintero, y decidí que no solo 
Figura 8 Café Gijón. Archivo Inza. Biblioteca ETSAM

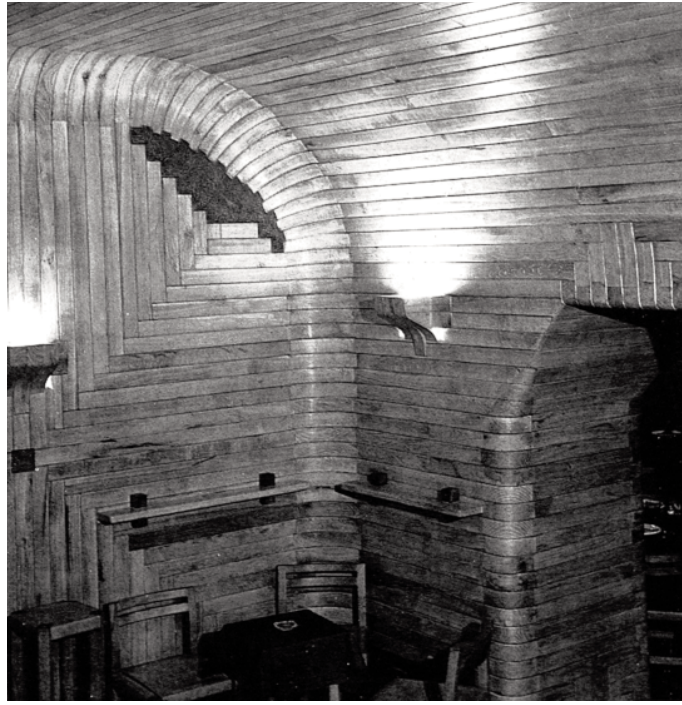

había que hacerle al sótano un "jersey de madera", sino hacerlo de tarima para lograr una cierta continuidad; y para llevar el juego hasta sus extremos últimos, decidí crear en el entarimado una regla de juego: No se debía encontrar una testa con una veta más de una vez. Y como cualquier juego de reglas esta lleva a situaciones totalmente diabólicas.....Y entonces el equipo trabaja y entiende lo que tiene que hacer: en este caso llevar hasta sus últimas consecuencias un concepto de continuidad de material empleado en la ocasión. De modo que sea posible pasar un dedo por una tabla, en todo el restaurante, hasta salir a la calle sin levantarlo". (Castro 1971)

Como resultado encontramos un laberinto táctil y mágico que se despliega por suelos, paredes y techos, planteando una coordinación de elementos que superan lo ornamental y nos introducen en su propia dinámica. Y sin pretender tratar esta obra como una pieza artística, se debe señalar que la plasticidad que inunda la idea y la obra, parece inevitablemente relacionada con procesos y artistas que están traba-

Figura 9. Café Gijón. Archivo Inza. Biblioteca ETSAM jando en procesos plásticos similares (figuras 8 y 9):

"Esta concepción del espacio interior como sujeto de un desarrollo plástico, sometido a una ley que opera en todos y cada uno de sus puntos y aspectos, viene a coincidir con varios de los más avanzados experimentos de las artes puras - por usar una terminología ya aceptada- llevados a cabo du $\neg$ rante los últimos años. Recordemos las experiencias de Fontana, de Scheggi, de Ceroli, de Soto... Todos estos pintores han dado pasos decisivos hacia la integración de las artes retomando el concepto -olvidado incluso por muchos arquitectos- de la modulación de espacios como determinante una y mil veces señalada por Zevi del lenguaje verdaderamente arquitectónico. Los elementos determinantes de Fontana han sido, según las ocasiones, la evolución espacial del tubo luminoso, las superficies curvas, intactas y superficies planas laceradas; el de Schegui, la perforación seriada del muro; el de Soto, la vibración cromática de una serie de elementos lineales yuxtapuestos. Como ya he dicho, Inza ha optado por la continuidad". (Crespo 1967)

De nuevo el trabajo se volvió a hacer a pie de obra y no fue fácil. Las paredes no eran paralelas, ni la bóveda regular, ni las esquinas formaban ángulos rectos, así que se dio un tendido de yeso sobre el que se trazó el entarimado y se ocultaron los canales de aire acondicionado intentando borrar cualquier huella mecanicista. Se construyó sobre la marcha ya que de poco valdría un plano. Muchos elementos como la barra del bar, la escalera, etc, producen planos, superficies curvas y encuentros complicados que se tratan de resolver de acuerdo con la regla prevista. La tarima de madera no presenta problemas en el suelo ni en las paredes donde se redondean los encuentros y esquinas y se resuelven en curva, con rodillos también de roble (figuras 10 y 11).

Inza asume que su método puede tener excepciones y errores, pero éstos deberán ser asumidos por la regla prefijada. La curva de la bóveda tiene más desarrollo que el plano del suelo y esto produce que a veces se encuentren varias vetas. En esos puntos donde concluyen muchas vetas aparecen nudos de madera resaltadas con un cambio de textura: son las excepciones. El problema muestra una dificil salida, pero es aquí donde se afirma y cobra entidad, la idea organicista. "El esquema del árbol, de la formación natural de la madera, se impone como solución. Unos "gajos"

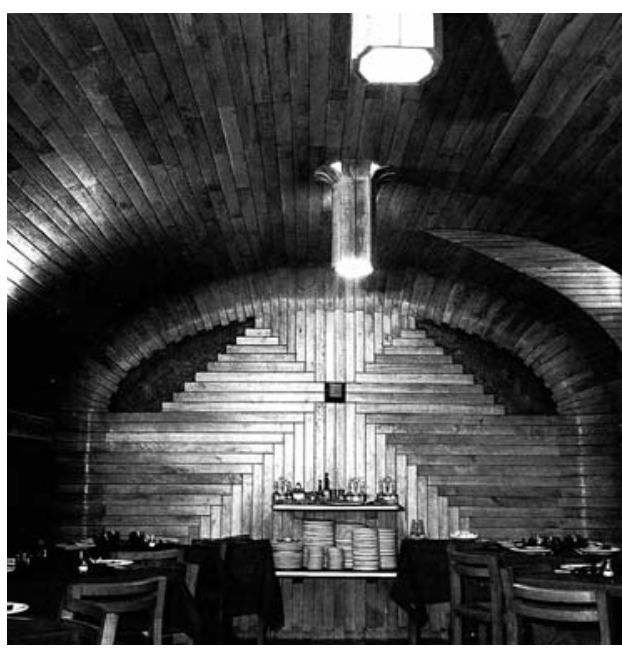




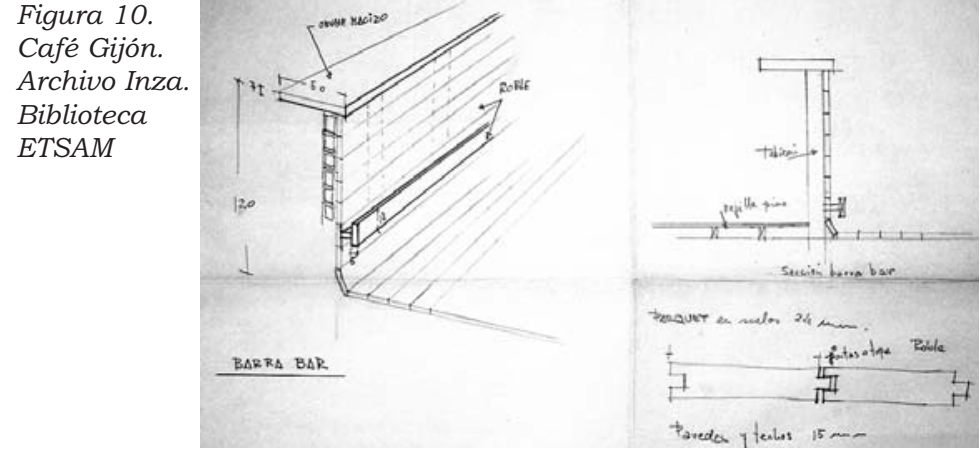

de madera de nogal son incrustados entre las vetas y las testas de roble del revestimiento: esos gajos ejercen función de nudos. La idea organicista ha venido a resolver el problema. La falta de simetría absoluta es una característica que, lejos de restar sentido a la obra, viene en apoyo de la flexibilidad orgánica". (Crespo 1967)

No se trata de establecer una ley ensimismada y arbitraria, sino de asumir las especificidades del material, sublimar $\neg 10$ y encontrar asi las pautas de un orden que rijan toda la obra (Arnuncio 1991). Inza asume y trabaja con el error y nos propone una regla que no es aleatoria sino que tiene que ver con el espacio al que se enfrenta y con las características intrinsecas del material constructivo que utiliza. Es una ley fiel al material (en este caso la madera) al que se confia toda la expresividad del espacio.

Como en la obra anterior no existe una forma previa sino un método. Y a él queda supeditada la forma como un resultado (entre los posibles) de su interacción con la construcción. El módulo rectangular elegido, habitualmente asociado a geometrias racionalistas, se desarrolla según un método poco rígido que permite las excepciones logrando al final una unidad flexible y natural. Podría decirse también que la ductilidad del tratamiento y las transiciones de las superficies en curva le dan al conjunto un discreto carácter modernista. El Café Gijón también tuvo una exitosa

Figura 11. Café Gijón. Archivo Inza. Biblioteca ETSAM

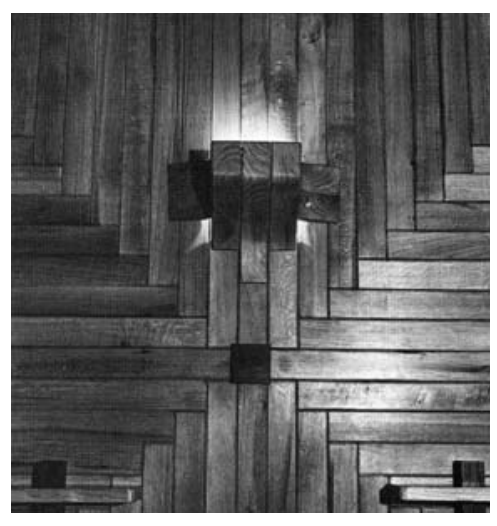

difusión como su publicación en la revista Domus (1963) o en la revista alemana M.D. Moebel interior design (1965) donde ocupó la portada.

Esta obra, que Inza realizó con treinta y tres años, demuestra como pocas una gran contención expresiva y una temprana madurez. Confia desde este momento en afrontar los proyectos desde una metodología establecida: "Las cosas que se plantean sobre una norma es sabido que duran siempre. La norma puede caer en desuso pero seguirá viviendo quieta hasta que llegue su nueva hora. Esto sucede con la obra de todo creador que haya planteado y seguido en ella- una regla de juego, por así decir (Castro 1971).

Vuelve por tanto en el café Gijón a utilizar una economía de medios materiales y de sistemas constructivos, una continuidad material y a fijar unas reglas de actuación (lo mismo que en la galería de Arte Sacro se hacía con la estructura).

\section{Conclusiones}

No dispuso Inza de materiales "ricos" sino humildes. Encontramos la riqueza en la sofisticación del método y en el ennoblecimiento del material mediante la explotación al máximo de cada uno de ellos para alcanzar la mayor expresividad con los menores medios. Material, construcción y estructura se mezclan constantemente y sus fronteras son a veces dificiles de definir. Y lo mismo ocurrirá en obras posteriores como por ejemplo en la fábrica de embutidos "El Acueducto" (Segovia.19631966) su obra más conocida. ${ }^{6}$ En ella es fácil apreciar algunos intereses que proceden y se establecen en estas primeras obras de juventud como son la continuidad material o el uso de un único material modesto, en este caso un ladrillo de tejar de la zona.

En vez de antitecnológico, se podría decir que su arquitectura asume la condición, tan actual, de baja tecnología. Baja tecnología que sin embargo, como se ha visto en estos ejemplos, no significa renuncia. Baja tecnología de estudiada elaboración en cuanto al material de trabajo (que siempre es el que tiene a mano) pero no en cuanto a los procesos con los que se aplica. La materialidad de estas obras (y de la arquitectura de Inza en general) podría inducirnos a error y entenderlas como ejercicios provincianos y tradicionalistas. Antes de cometer ese error cabria recordar que Inza fue durante años Secretario de redacción de la revista Arquitectura y publicó por vez primera (y por tanto las conocía) las pala- 
bras de Reyner Banham, cuando éste dijo en 1961 que el Nuevo Brutalismo iba siempre acompañado de una actitud en el uso de los materiales "tal y como se encuentran" y ello trae consigo " $1^{\circ}$, una decidida honradez en su uso (paralela a la negativa de adoptar una actitud selectiva frente a los hechos históricos) y $2^{\circ}$, una insistencia en el que todas las cualidades de un material son igualmente valiosas" (Banham 1961).

La arquitectura de Inza en lo material es claramente brutalista, pero de un brutalismo hecho en un país con un nivel tecnológico que no es el de los Smithson. Sin embargo la mirada es igual de contemporánea y se caracteriza por: una economía de medios, pocos sistemas constructivos, dejar vistos los procesos, sinceridad constructiva, continuidad material, aspiración a espacios "monomatéricos", y una clara condición actual de baja tecnología.

Habria que precisar entre construcciónestructura y construcción-revestimiento. En las dos obras presentadas intervienen los dos aspectos aunque la idea de estructura solo en la primera. El revestimiento es, por el contrario, clave en ambas. Pero en todo subyace la condición artesanal, el material manejado a mano y con dimensiones reducidas que lo hagan posible $y$ sin medios mecánicos auxiliares. Las decisiones de radical continuidad y unidad del material (ambas cercanas a un elementalismo moderno) son las que principalmente lo alejan de una condición antigua y decididamente tradicional.

Mantendrá Inza, de hecho, ese equilibrio entre lo artesano, la ejecución esmerada y una cierta mirada brutalista que lo liga al momento internacional. Retomando el inicio de este escrito, cabe decir que estas dos pequeñas obras aquí analizadas confirman la búsqueda de un método flexible (errores incluidos) para producir arquitectura apoyándose en gran medida en el diálogo que se establece entre construcción, forma y materia. Un diálogo que tiene como primera derivada la lección (bien evidente y actual) de la idea de "hacer mucho con muy poco".

\section{Notas}

1. Proyecto catalogado en el Archivo Inza con el $\mathrm{n}^{\circ}$ 62: Proyecto de instalación comercial Tapicerias Gancedo en c/ Velázquez 21. Madrid, febrero de 1961.

2. Proyecto catalogado en el Archivo Inza con $\mathrm{n}^{\circ}$ 012: Proyecto de un comedor de autoservicio para un camping en "La Mesquida". Mallorca, enero 1958.
3. Proyecto catalogado en el Archivo Inza con $n^{\circ} 69$ : Proyecto Fin de Carrera. Cementerio Militar, Madrid, junio 1959.

4. Entrevista con Andrés Perea. 27 de mayo de 2010. Madrid.

5. Proyecto catalogado en el Archivo Inza con $n^{\circ}$ 69: Proyecto de Reforma del Café Gijón, Madrid, abril 1962.

6. Proyecto catalogado en el Archivo Inza con $n^{\circ} 57$ : Proyecto de fábrica de embutidos para Félix Postigo Herranz. S. A. Segovia, febrero 1963.

\section{Bibliografia}

Archivo Inza. Depositado en la Biblioteca de la ETSAM.2011.

Arnuncio, Juan Carlos. 1991. Francisco de Inza. Comentarios sobre la forma arquitectónica. BAU. 5-6: 145-155.

Art d'Eglise 1963. N. 123, segundo semestre. Bélgica.

Aguilar O.P, FR., José Manuel de. 1978. Un arquitecto-artista. Curro de Inza. ARA: Arte Religioso Actual, 553-7.

Banham, Reyner.1961.Balance 1960. Arquitectura, 26: 29-32. (Titulo original: Stocktaking. Architectural Review, febrero 1960. Londres).

Bohigas, Oriol. Contra una arquitectura adjetivada. Barcelona: Ed. Seix Barral, 1996.

Castro Carmen.1971. Francisco de Inza. Fábrica de chorizos en Segovia. (Los Arquitectos critican sus propias obras). Arquitectura, 153: 53-58.

Centellas Soler, Miguel. 2010. Los pueblos de colonización Fernández del Amo: arte, arquitectura y urbanismo. Barcelona: Fundación Caja de Arquitectos.

Crespo, Ángel. 1967. Una obra de Francisco Inza. Nueva Forma, 17: 47.

Domus. 1963. Noviembre, 408: 30. Milán.

Fullaondo, Juan Daniel. 1968. La Escuela de Madrid. Arquitectura, 118: 11-23.

Inza, Francisco. 1961. Tienda de tapicerias de Francisco Inza. Arquitectura, 36: 27-30

Inza, Francisco.1962. Templo y Altar. Galeria de Arte Sacro. Arquitectura, 41: 22-24.

Inza, Francisco. 1963. Lo expresivo y lo representativo. Coloquios sobre iglesias. Arquitectura 52: 35-37.

Inza, Francisco. 1963 b. Temas de Arquitectura. Madrid.

Inza, Francisco. 1963 c. Café Gijón. Arquitectura, 55: 25 , julio.

Inza, Fco. 1966. Comentarios a una conferencia de Félix Candela. Arquitectura, 88: 1-6.

López Quintans, P. Alfonso. 1963. Coloquios sobre iglesias. Arquitectura, 52: 37.

M.D. 1965. M.D. Moebel interior design 5/65: 237 ..

Moya, Luis. 1963. Coloquios sobre iglesias. La pobreza y la sinceridad. Arquitectura 52: 3435.

Ruiz Cabrero, Gabriel. 2001.El Moderno en España. Arquitectura 1948-2000, p. 48. Sevilla: Tanais Ediciones.

Revista Zodiac. 1969. N.18. Milan.

Tena, Luis. 1999. Memoria de Curro Inza. Arquitectura 318:48-51.

Autor. 2013. La arquitectura de Curro Inza: una aproximación critica y proyectual. Tesis doctoral. ETSAM. Madrid

Fecha de entrega del artículo: 14/04/ 15

Fecha de aceptación:

$07 / 07 / 15$

Artículo sometido a revisión por dos revisores independientes por el método doble ciego. 